\title{
Development of Safe and High Power Batteries for HEVs
}

\author{
Taison Tan*, Hiroyuki Yumoto*, Derrick Buck*, Bob Fattig*, and Chad Hartzog*
}

Safety is one of the most important concerns for lithium-ion batteries due to the high energy density of the cells. In battery packs for HEV, PHEV, or EV applications, there exist dozens of lithium-ion cells that are connected in series and/or parallel to create a pack with high voltage and that is capable of discharging and charging with high currents. Managing such a battery pack therefore requires increased safety management compared to a cellphone or laptop battery. Not only is the management of the safety important during usage of the pack but also during assembly and maintenance. The high voltage conditions ( $>100 \mathrm{~V})$ that exist in HEV battery packs can pose potential hazards for workers and auto mechanics. The need for increased safety controls increases with higher voltage systems. Therefore, improving the safety of the lithium-ion battery via the cell chemistry can lead to a reduction of cost for the HEV, PHEV, and EV battery by eliminating the need for costly battery management and cooling systems.

In order to improve the safety of lithium-ion batteries for use in HEV, PHEV, and EV applications, EnerDel has investigated various battery active materials using $2 \mathrm{Ah}$ sized prototype cells. These cells were tested according to the U.S. Advanced Battery Consortium (USABC) test FreedomCAR manual. The tests included power capability, cycle life, calendar life, and cold cranking tests. In addition to the tests in the FreedomCAR test manual, some abuse tests such as overcharge and nail penetration were also carried out.

Keywords: Lithium-Ion Battery, Lithium Titanate, Hybrid Electric Vehicle (HEV), High Power, Safety

\section{INTRODUCTION}

EnerDel is a lithium-ion battery company located in Indianapolis, Indiana, focused on delivering batteries for HEV, PHEV, and EV applications for the automotive industry. The facility in Indianapolis has the full utility and infrastructure for mass producing lithium-ion batteries. The facility was built for the purpose of cell and pack manufacturing.

For the HEV application, EnerDel's technology provides a battery application focusing on Safety, Performance, Quality, and Life. These four key aspects are achieved in EnerDel's battery technology through the choice of active materials, the mechanical architecture, thermal management, battery management, and system interface. It is the combination of these qualities that allows EnerDel to provide the best battery solution for HEV market.

\section{CELL CHEMISTRY}

EnerDel's choice of active materials for the cell chemistry suitable for the HEV automotive application

* EnerDel, Inc.

8740 Hague Rd, Bldg 7

Indianapolis, IN 46256

(c) 2008 WEV Journa is $\mathrm{LiMn}_{2} \mathrm{O}_{4}$ - spinel (LMO) for the cathode and $\mathrm{Li}_{4} \mathrm{Ti}_{5} \mathrm{O}_{12}$ (LTO) for the anode. Figure 1 shows the discharge curve for an LMO/LTO cell discharged at a rate of $1 \mathrm{C}$ at $30^{\circ} \mathrm{C}$. The profile is sloped and not flat, allowing for the determination of state of charge based on voltage. The operational voltage of an LMO/LTO system is lower than most conventional lithium-ion chemistry systems.

\subsection{Power Capability}

The choice of LTO as the anode material provides the LMO/LTO system with high power capability. Figure 2 shows the rate capability of a 1.8Ah LMO/LTO cell. The capacity achieved at the high discharge rate of 50C is almost the same capacity achieved at a $2 \mathrm{C}$ discharge rate. This high rate capability can be attributed to the lower impedance of the LTO anode compared to graphite anodes.

Figure 3 shows the power capability of the LMO/LTO cell at various depths of discharge (DOD). The LMO/ LTO cell can achieve the high power capability over a wide range of DOD, therefore providing a wide range of usable energy. Although the operational voltage of the LMO/LTO system is lower than most other conventional lithium-ion chemistries, the usable energy range where 


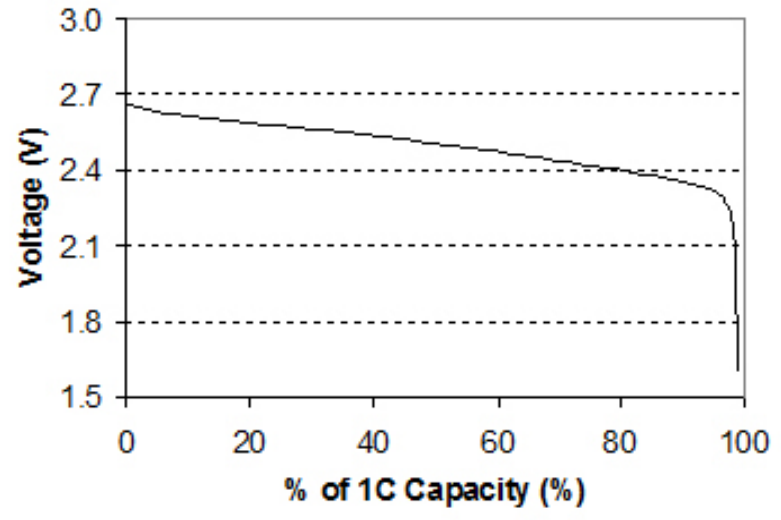

Figure 1: $1 \mathrm{C}$ discharge of an LMO/LTO cell at $30^{\circ} \mathrm{C}$

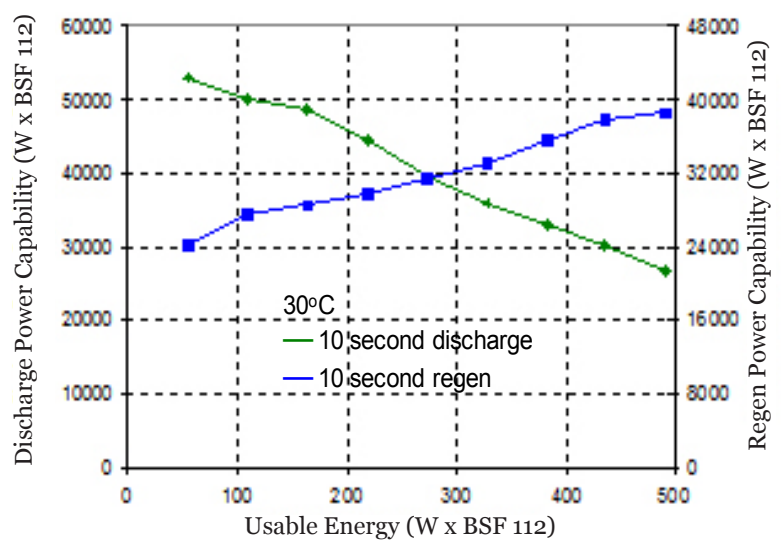

Figure 3: Power capability of the LMO/LTO cell calculated from a Low Hybrid Pulse Power Capability test as described by the USABC FreedomCAR Test Manual

the power is available is also much wider.

\subsection{Low Temperature Performance}

Most conventional lithium-ion chemistries cannot perform at low temperatures without a large degradation of capacity or power. In addition, systems with carbon based anodes risk the possibility of lithium dendrites forming when discharged at low temperatures. This phenomenon is not a risk with the LMO/LTO chemistry since the nominal voltage of the LTO anode is approximately $1.5 \mathrm{~V}$, providing a potential that does not allow for the formation of lithium dendrites which may lead to shorts in the cell.

Figure 4 shows the power capability of the LMO/LTO cell at $-30^{\circ} \mathrm{C}$. The test was conducted at three different depths of discharge (DOD) in order to determine the effect of DOD on power capability. From 25\% DOD to $75 \%$ DOD, the LMO/LTO cell was capable of delivering

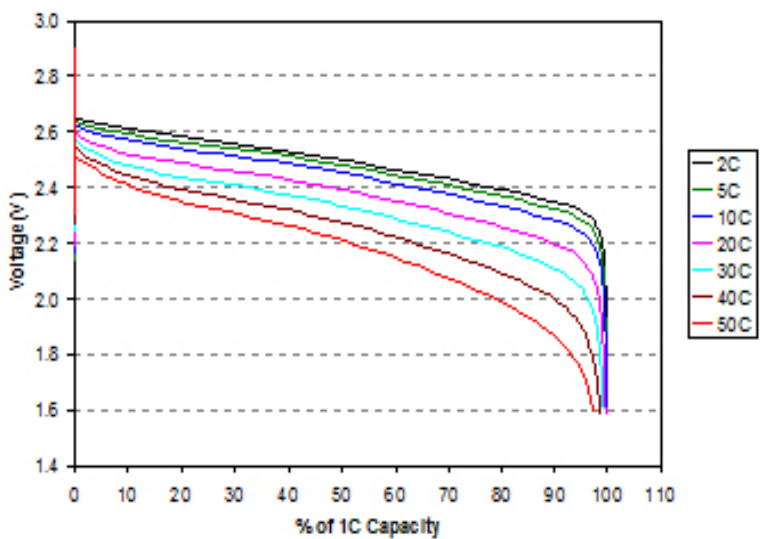

Figure 2: Various discharge curves of a 1.8Ah LMO/LTO system discharge at rates varying from $2 \mathrm{C}$ to $5 \mathrm{OC}$ at $30^{\circ} \mathrm{C}$

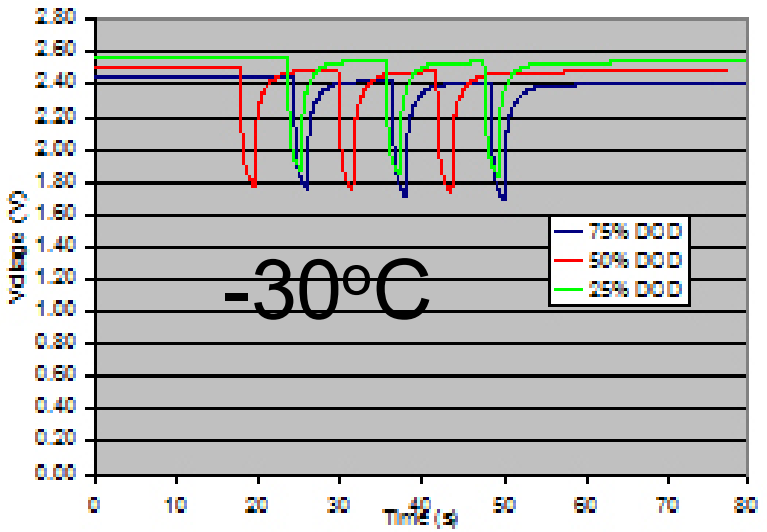

Figure 4: Cold cranking pulses at three depths of discharge at $-30^{\circ} \mathrm{C}$. Each cold cranking pulse is equivalent to $5 \mathrm{~kW}$.

the required $5 \mathrm{~kW}$ of power for three separate pulses at $-30^{\circ} \mathrm{C}$. Figure 5 shows the capacity of the LMO/LTO cell discharge at a $1 \mathrm{C}$ rate at various temperatures. The capacity achieved at $-30^{\circ} \mathrm{C}$ is more than $90 \%$ of the capacity achieved at $30^{\circ} \mathrm{C}$. This low temperature capability of the cell provides a useful capability of the cell over a wide range of operating temperatures making the LMO/LTO cell chemistry suitable for automotive applications.

\subsection{Long Life Capability}

Both active materials of $\mathrm{LiMn}_{2} \mathrm{O}_{4}$ and $\mathrm{Li}_{4} \mathrm{Ti}_{5} \mathrm{O}_{12}$ are of spinel structures providing the materials with high stability under charge and discharge. During intercalation and de-intercalation of lithium ions, the LTO material experiences approximately $0.2 \%$ volume change compared to graphite which experiences about a $9 \%$ volume change. This characteristic of the LTO 
material is the reason why it is also known as a zero strain material. In the fully charged state, the LTO structure becomes a rock salt structure which is also a stable structure. The stability of both materials during charge and discharge allows the LMO/LTO cell chemistry to provide very stable cycle life characteristics.

Figure 6 shows the cycling results of an LMO/LTO cell cycled at a $5 \mathrm{C}$ rate for both charge and discharge at $55^{\circ} \mathrm{C}$ for $100 \%$ depth of discharge. The results show the very stable cycling capability of the LMO/LTO system.

\section{MECHANICAL ARCHITECTURE}

\subsection{Cell Design}

EnerDel's choice for the cell architecture is the use of a prismatic design. This use of a prismatic design provides the cell with a large surface area for better heat dissipation compared to a cylindrical design. Figure 7 shows two examples of the prismatic design for the LMO/LTO cells. Table 1 shows the specifications of the two prismatic designs. This benefit of the prismatic design allows for a variety of cooling options since the heat can be dissipated easily. In addition, the LMO/ LTO system does not generate much heat at high rates due to the cell's high efficiency as shown in Figure 8 and Figure 9.

Thermal testing of the LMO/LTO cell has demonstrated the low heat generation characteristic of the LMO/ LTO cell. Figure 10 shows the result of cycling a $1.8 \mathrm{Ah}$ $\mathrm{LMO} / \mathrm{LTO}$ cell inside a $50^{\circ} \mathrm{C}$ oven continuously for over one hour. The temperature on the surface and inside the cell did not exceed $60^{\circ} \mathrm{C}$ even though surrounding temperatures were at $50^{\circ} \mathrm{C}$. The temperature fluctuated between $55^{\circ} \mathrm{C}$ and $58^{\circ} \mathrm{C}$ depending upon whether the cell was charging or discharging. These results indicate the low heat generation of the LMO/LTO system which allows the system to be thermally managed with a

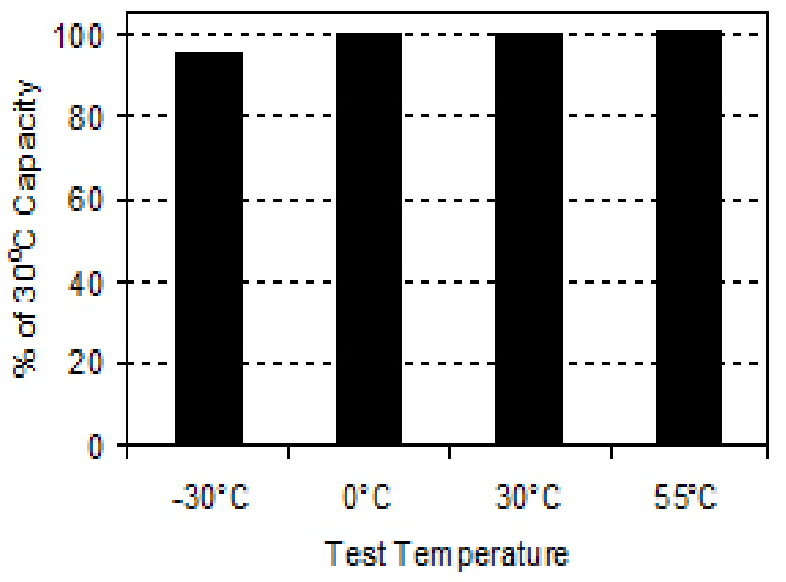

Figure 5: Capacity discharged at $1 \mathrm{C}$ rate at various temperatures

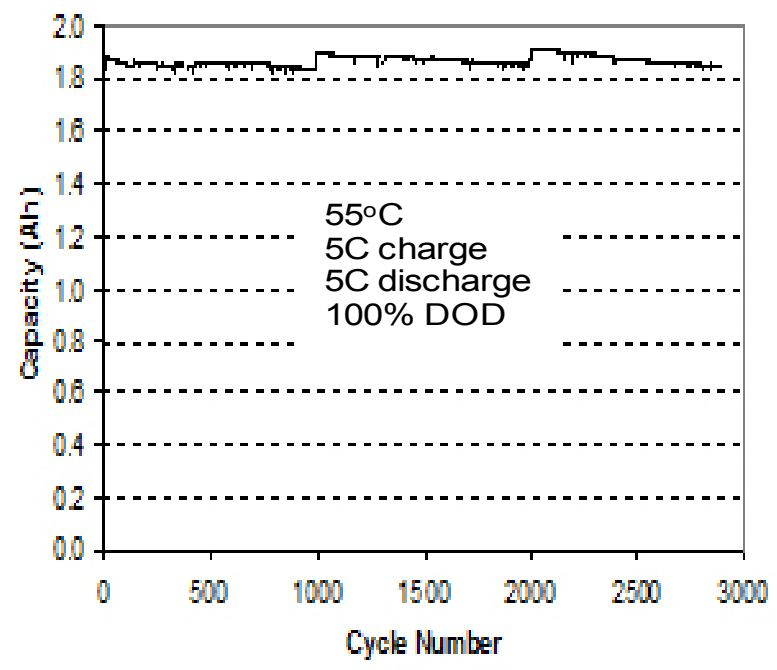

Figure 6: $5 \mathrm{C}$ cycling at $55^{\circ} \mathrm{C}$ for $100 \%$ depth of discharge. The capacity remains flat for almost 3000 cycles.

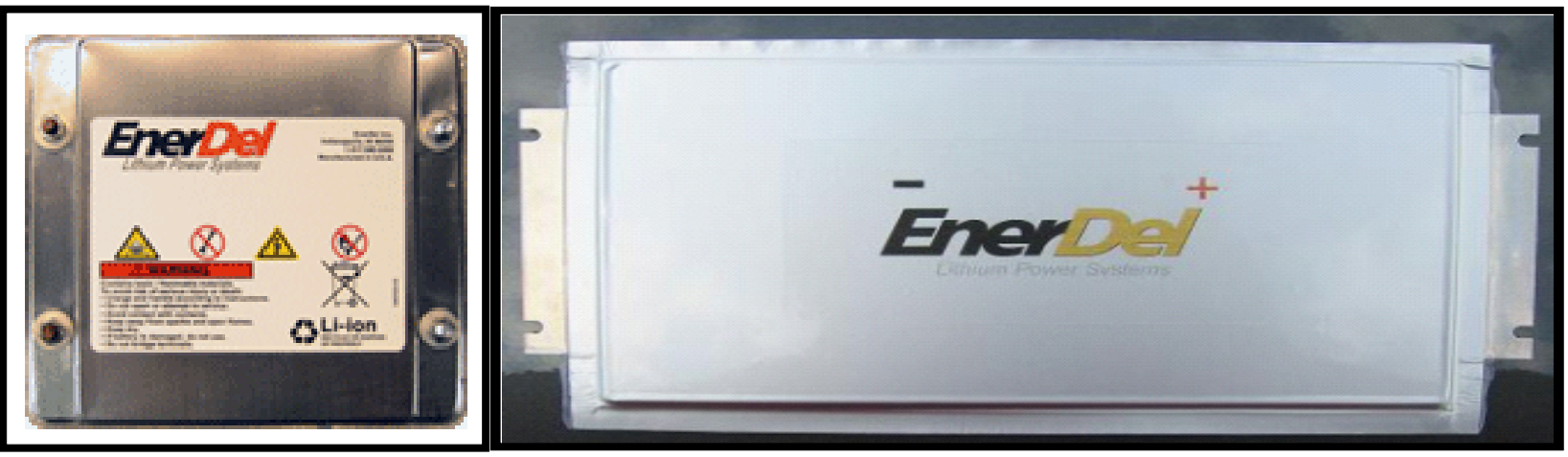

Figure 7: Metal case design for a CD size, 1.8Ah LMO/LTO cell (left) Flexible packaging design for an A5 size, 5Ah LMO/LTO cell (right) 


\begin{tabular}{|c|c|c|}
\hline & CD Size & A5 Size \\
\hline Nominal Capacity & 1.8 Ah & $5 \mathrm{Ah}$ \\
\hline Nominal Voltage & $2.5 \mathrm{~V}$ & $2.5 \mathrm{~V}$ \\
\hline $\begin{array}{l}\text { Dimensions } \\
\text { (connections included) }\end{array}$ & $145 \mathrm{~mm} \mathrm{~W}, 130 \mathrm{~mm} \mathrm{~L}, 5 \mathrm{~mm} \mathrm{~T}$ & $200 \mathrm{~mm} \mathrm{~W}, 111 \mathrm{~mm} \mathrm{~L}, 5.8 \mathrm{~mm} \mathrm{~T}$ \\
\hline Packaging & Metal or Laminate & Metal or Laminate \\
\hline
\end{tabular}

Table 1: Specifications for the CD size and A5 size cell designs

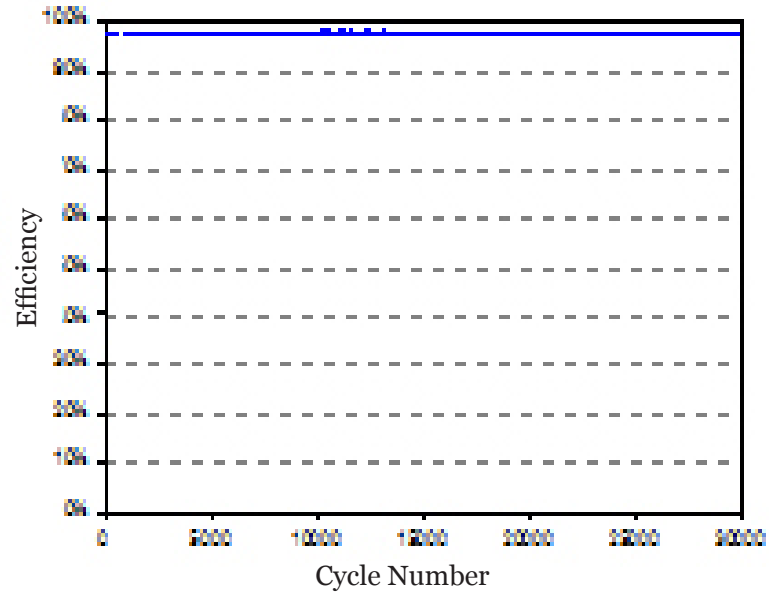

Figure 8: 30,000 energy efficiency cycles maintaining $97 \%$ efficiency at $30^{\circ} \mathrm{C}$

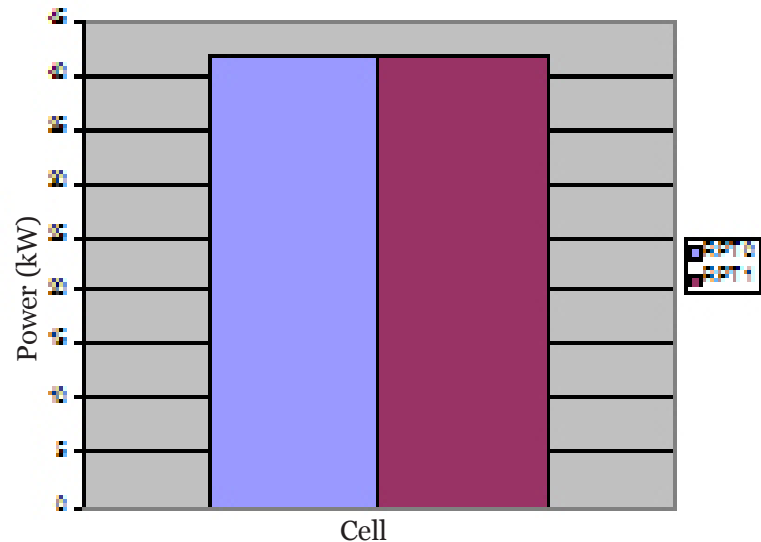

Figure 9: Reference Performance Test o (RPT o) and Reference Performance Test 1 (RPT 1) show no loss of power after 30,000 energy efficiency cycles

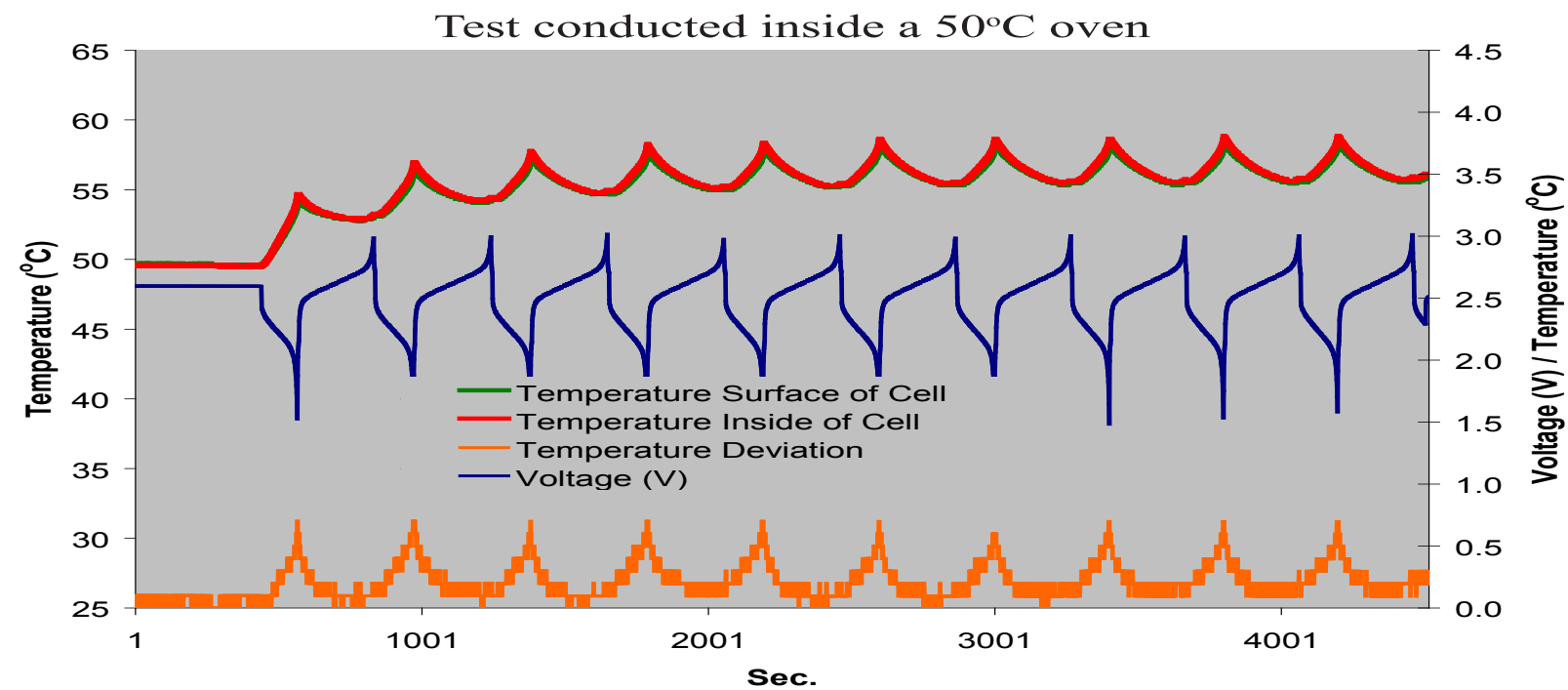

Figure 10: Results of thermal testing of a 1.8Ah LMO/LTO cell. The cell was cycled at a $10 \mathrm{C}$ charge rate and $20 \mathrm{C}$ discharge rate continuously for more than one hour inside a $50^{\circ} \mathrm{C}$ oven. 
variety of options from air cooling to liquid cooling.

\section{SYSTEM DESIGN}

EnerDel's Lithium Power System (Figure 11) provides a safe, small, light, high power replacement for $\mathrm{NiMH}$ packs. EnerDel's modular approach to system design provides the flexible architecture to satisfy the needs of various applications without impacting the basic methods of assembly. The design also provides the option to thermally manage the system by means of air or liquid cooling media. The system design and manufacturing processes have been developed for ease of assembly and include various error proofing features. The system provides a robust solution capable of meeting the challenge of today's stringent automotive requirements.

Prismatic cells provide an ideal form factor for efficient heat removal due to the available surface area in contact with heat sinks positioned on each side of the cells within the module stack. The thin profile of the prismatic cell allows for flexibility and stackable form factors for use in various pack designs. The terminals on the prismatic cells also provide for alternate methods of material joining for electrical series or parallel configurations. All electrical interconnects are plated to eliminate any risk of galvanic degradation. Flexible circuits provide interconnects for voltage sense and thermal measurement, eliminating the need for discreet wires. Battery modules are encapsulated to maintain structural integrity over time and to provide protection from material ingress. Electrical control components are mounted in accessible compartments for ease of serviceability.

\subsection{System Safety}

As with all lithium-ion battery manufacturers, safety and system fault detection is a serious challenge. EnerDel continues to exercise the use of Design Failure Mode and Effects Analysis (DFMEA) system verification and validation to automotive standards in order to maintain safe operation of lithium battery systems. Safety is enhanced in the proposed system by utilizing cell level control of the entire battery system. It is further ensured by redundancies and checking for validity of the data which is reported by independent verification at various stages within the system.

\subsection{Pack Control Architecture}

EnerDel have developed a modular approach, sized to customer specifications with a master control system for vehicle interface. The modular approach requires that logical divisions of function be drawn within the system

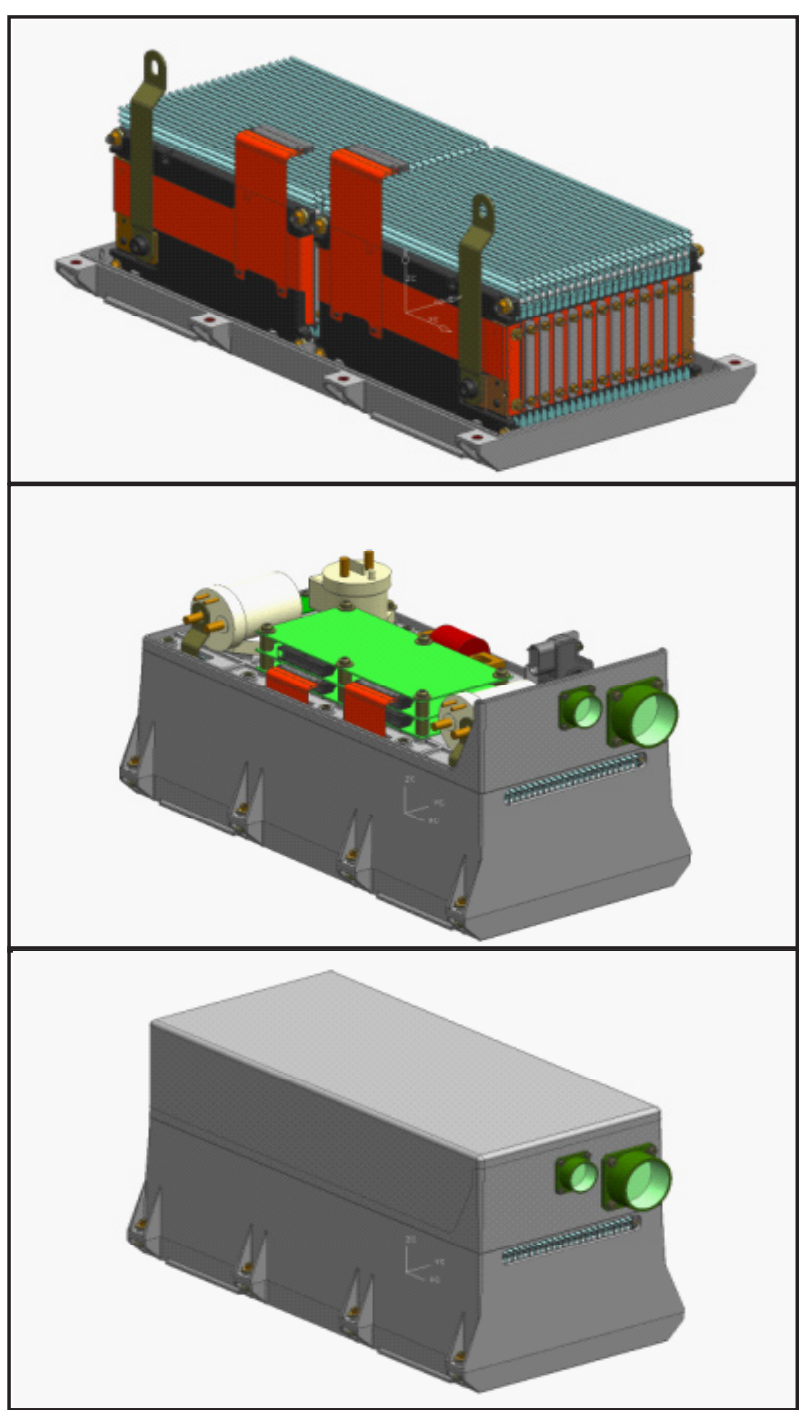

Figure 11: From top to bottom: Case removed to show module assemblies, cover removed to show system control components, fully assembled Lithium Power System

and EnerDel has already produced various prototypes of these types of systems. EnerDel's analysis of this system is that with our lower cell voltages, the overall controls cost does not increase. This is accomplished by making smaller circuitry changes at the modular level, where addition of circuitry or complexity is much more efficient. Therefore, at a system level, the overall complexity and cost is essentially equal to systems using standard voltage cells $(3.6 \mathrm{~V})$. Figure 12 shows an existing prototype system.

EnerDel currently has the prototypes for controls of a high voltage system up to $700 \mathrm{~V}$ or more. This 


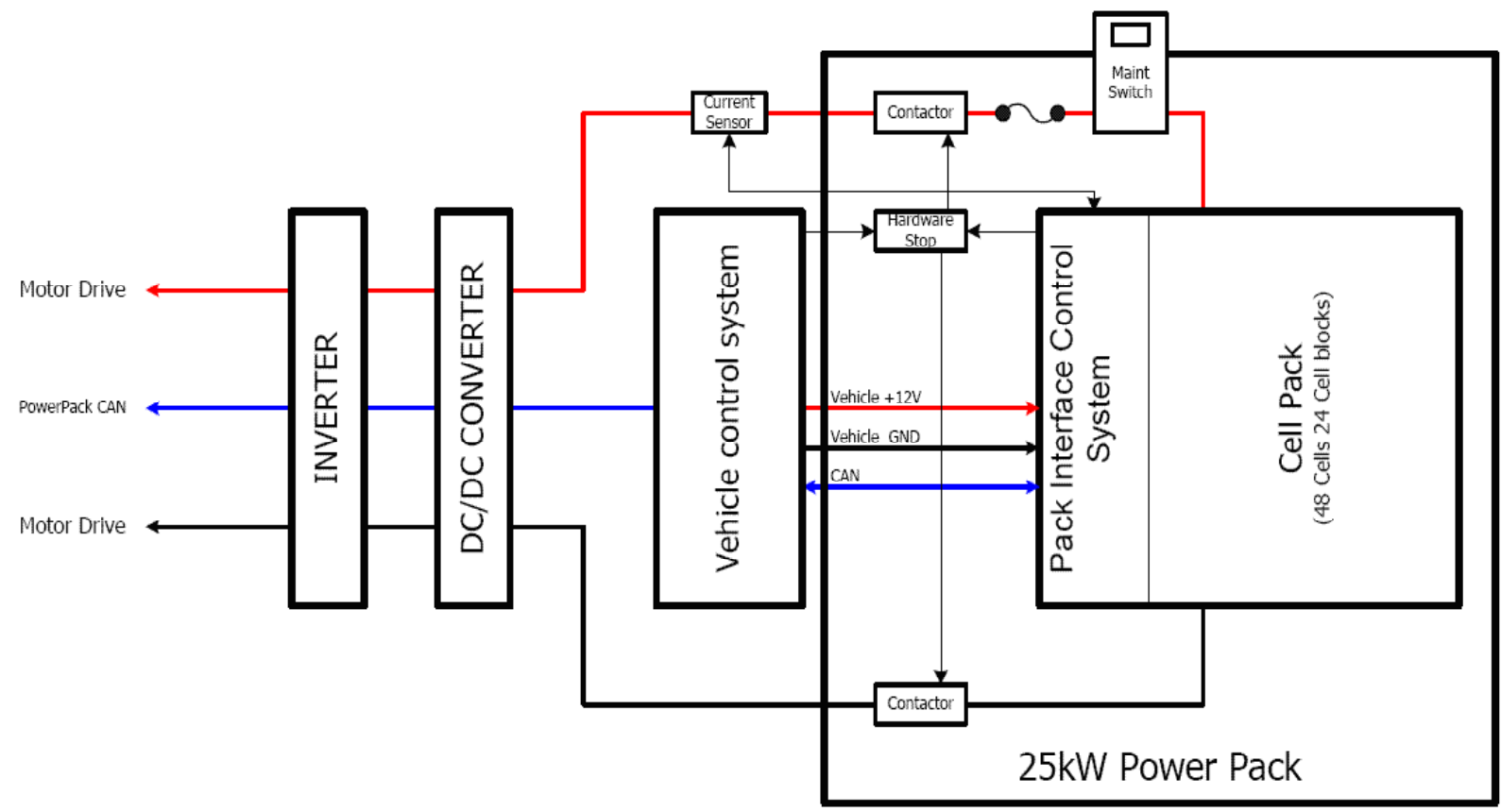

Figure 12: A representation of the functional architecture organization based on EnerDel control technology Actual physical divisions will depend upon final implementation

allows for extremely flexible control architecture. With EnerDel's advanced architecture, the total accuracy over the entire temperature range of $-40^{\circ} \mathrm{C}$ to $+85^{\circ} \mathrm{C}$ will approach $1 \%$ SOC.

\subsection{Pack Control Function}

Basic requirements of the pack management system would include reporting and controlling cell State of Charge (SOC), cell balance, thermal management and complete charge and discharge control functionality. All portions of the battery system will be measured and checked on a continuous basis by the system controls for the life of the system. This includes measurements of cell voltage, pack voltage, thermal zones and system current. Many layers of system controls redundancy are used to validate that the system is functioning and measuring correctly. EnerDel has demonstrated the ability to create advanced custom algorithms to improve system performance and prediction of cell characteristics under load. System diagnostics are continuously employed to detect failures and or faults within the battery pack.

All information is utilized to deliver total performance of the energy system to the vehicle. This, in conjunction with extremely high rate cells allows for a larger utilization of the total charge curve of the system. In contrast, standard lithium and nickel systems utilize a relatively small SOC region, requiring significant over sizing of cells in addition to expensive thermal management systems to prevent markedly rapid thermal generation.

\section{CONCLUSION}

The LMO/LTO system chosen by EnerDel for the automotive market is a system that provides excellent discharge and regen power capability. These high power characteristics allow for the design of a smaller energy density system with better safety to provide the required currents. This high power capability is also still available at such low temperatures of $-30^{\circ} \mathrm{C}$. The LMO/LTO system can provide a safe/long life system that is especially suitable for mild and medium hybrid electric vehicles. This cell chemistry is packaged in a mechanical architecture that is designed to increase the safety and life of the battery system. EnerDel offers a total battery solution, providing fully integrated cells and system management controls.

\section{ACKNOWLEDGEMENT}

Portions of this work were supported by USABC/DOE, Idaho National Laboratory and Argonne National Laboratory. 


\section{AUTHORS}

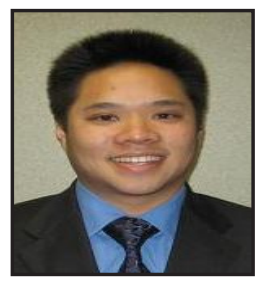

Taison Tan, Research and Development Manager, obtained his Bachelor's of Science from Caltech in 1998 and his Ph.D. from UCLA in 2002. Dr. Tan currently manages the research and development activities at EnerDel. Dr. Tan previously worked at Quallion, researching and developing batteries for various applications ranging from medical to aerospace. Phone: 317-585-3468, fax: 317-585-3400, ttan@enerdel.com.

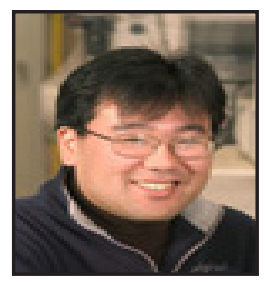

Hiroyuki Yumoto, Director of Cell Development, leads all of EnerDel's lithium ion cell activities. Mr. Yumoto has a Bachelor's degree in Industrial Chemistry and a Master's degree in Polymer Chemistry, both from Kyoto University, and also a Master's degree in Material Science from the University of Southern California. Phone: 317-585-3422, fax: 317-585-3400, hyumoto@enerdel.com.

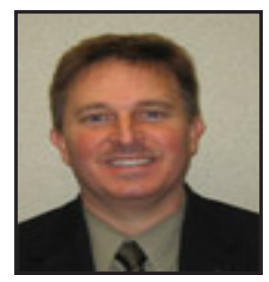

Derrick Buck, Director of Battery Systems Integration, leads all of EnerDel's development of integrated lithium battery systems and associated manufacturing methods. Mr. Buck has a Bachelor's of Science degree in Mechanical Engineering Technology from Purdue University. Phone: 317-5853402, fax: 317-585-3400, dbuck@enerdel.com.

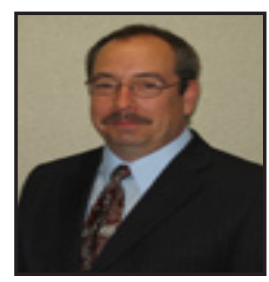

Bob Fattig, Engineering Manager, leads all activities associated with the development of custom battery management systems. Mr. Fattig has an Associate's of Applied Science in Electronics Engineering Technology and a Bachelor's of Science in Automated Manufacturing Technology from ITT Technical Institute. Phone: 317-585-3410, fax: 317-585-3400,bfattig@enerdel.com.

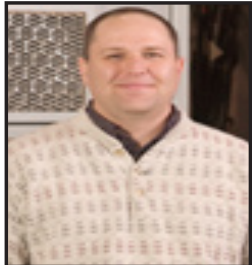

Chad Hartzog, Systems Controls Engineer - Technical Lead, is responsible for the design, development, and validation of all battery management electronic controls. Mr. Hartzog is pursuing his Bachelor's of Science in Electrical Engineering at Purdue University. Phone: 317-585-3411, fax: 317-5853400, chartzog@enerdel.com. 